\title{
Labor Migrants in Russia: Sociocultural Portrait
}

\author{
Svetlana Guzenina ${ }^{1},{ }^{*}$ Elena Radchenko², Khatira Kamalova ${ }^{3}$, Ziba Aitmuratova ${ }^{3}$
}

\author{
${ }^{1}$ Derzhavin Tambov State University, Russia \\ ${ }^{2}$ Institute of contemporary art (ISI), Russia \\ ${ }^{3}$ Karakalpak State University named after Berdakh, Street named after Academician Ch. Abdirov, Uzbekistan \\ *Email: gyzenina39@gmail.com
}

\begin{abstract}
The article reveals the problems of interaction between people who come to Russia for work and the sociocultural environment of the host society, an essential component of which is the attitude of the local population to labour migrants.

Data from empirical studies show that relations with the host population are evaluated positively by labour migrants. In turn, the "sociocultural portrait" of migrants is formed by Russians based on their beliefs about the negative consequences of labour migration, despite such socially positive qualities of labour migrants as hard work, willingness to work hard and improve their lives. The authors emphasise the need for a detailed study of the impact of the sociocultural environment of the host society, the adaptive capabilities of labour migrants, as well as social practices of interaction between the host population and the authorities with labour migrants, which require timely legal and managerial decisions.
\end{abstract}

Keywords: Labour migration, Adaptation, Sociocultural portrait, Host society.

\section{INTRODUCTION}

Despite a relatively large number of publications that deal with the phenomenon of labour migration, several aspects have not been sufficiently studied by scientists. These include sociocultural aspects of adaptation of labour immigrants. Researchers identify many factors that affect the success of migrants adaptation to new conditions.

Specialists of the Norwegian University of science and technology, Rye J.F. and Slettebak M.H., studying the dynamics of incoming flows and the geographical distribution of labour migrants in rural regions, using the example of labour migrants from 11 countries of Eastern and Central Europe, concluded that, first, their distribution is heterogeneous; second, it correlates with the simultaneous action of three groups of factors: characteristics of the labour market, demographic profiles, and the degree of peripherality of localities [1].

Australian scientists Leung C. and Karnilowicz W. noted that supporting social relations are of particular importance for the successful psychological and academic adaptation of international students [2].

When analysing models of sociocultural adaptation of former CIS citizens in Israel, Lissitsa S. and Peres Y. revealed that immigrants from the CIS countries prefer to choose an acculturation model, that is, selective acceptance of the target culture while maintaining kinship with the native one [3]. The scientific work Tarasyev A.A., Jabbar J.B. [4] is devoted to similar issues in the context of labour migration.

Currently, migration, including labour migration, is becoming more and more widespread and an integral part of the life of the modern world, including Russia. One of the key roles here is played by the sociocultural environment of the host society, an essential component of which is the attitude of the local population to labour migrants. Various aspects of the integration potential of the host society are devoted to the scientific developments of sociologists Guzenina S.V., Voropaeva A.V., Marshak A.L. [5,6,7]. 
Scientific articles of recent years show that interest in the problem is growing since it is polyvalent and includes the tasks of studying:

- adaptation potential of the Russian population to the growing ethnic diversity $[8,9,10]$;

- dialogue between government and society [11];

- risk minimisation [12].

The Director of Institute for Demographic Research FCTAS RAS, S.V. Ryazantsev, in his scientific publications, focuses the attention of the scientific community on estimates of the number of official and illegal labour migrants, making labour migrants in Russia and improvement of the policy of state regulation of labour migration in the EEC and Russia [13].

\section{PROBLEM STATEMENT}

Empirical studies data shows that relations with the host population are evaluated positively by labour migrants. In turn, the "sociocultural portrait" of migrants is formed by Russians based on their beliefs about the negative consequences of labour migration.

A detailed "sociocultural portrait" of migrants was presented in a 2011 study conducted by the HSE CEPRR. The authors of the study distinguish three categories of migrants [14, p.239]: "permanent" or "long-term" migrants who practically do not leave the territory of Russia, except for rare trips to their homeland; "circular migrants" who periodically come (usually for working) and leave the territory of Russia; and the third category of migrants includes persons who firstly arrived in Russia. The countries of departure of first-time arrivals to Russia are usually the States of Central Asia, where the main flows of labour migrants originate [14, p.244].

The main types of employment of migrants: wholesale and retail; repair of motor vehicles and household goods - 36.3\%, construction - 22.6\%, municipal, social and personal services - $13.2 \%$, transport and communications $-8.3 \%$ of employees. Interestingly, relations with the host population are evaluated positively by labour migrants themselves (table 1) [14, p.251].
One of the main indicators of labour immigrants sociocultural adaptation is the extent of their participation in the cultural life of Russia, the assimilation of norms and values of the culture of the residence environment, opportunities for self-realisation. Researchers of Institute of sociology RAS concluded that the culture of the host society while remaining one of the leading factors contributing to sociocultural adaptation, needs innovative severe changes in terms of organisational measures, moral and value content, improving communication links, and giving them a national flavour [15].

Analysing the results of numerous studies on the attitude of Russian citizens to foreign workers, we can conclude that Russians still note many negative consequences of labour migration. At the same time, speaking about the "sociocultural portrait" of labour migrants, such socially positive qualities as hard work, willingness to work hard and improve their lives are also listed. The host community of the region is a fundamental component of the sociocultural environment and plays an essential role in the adaptation of labour migrants. But there are significant regional differences in the image of labour migrants. In this regard, we decided to conduct an author's sociological study to find out the relevance of the problem of labour migration for the population of a typical Russian city of the Central Federal district [16], as well as the attitude of residents to visitors and their cultural values.

\section{RESEARCH METHODS}

The author's sociological study "the role of the region host community in the labour migrants sociocultural adaptation " was conducted in April 2019, the sample consisted of students of 1-4 academic year studying at Tambov State University named after G.R. Derzhavin, $\mathrm{N}=115$, including 19 boys and 96 girls aged 18 to 25 years. The respondents were young Tambov residents, full-time students, as many of them themselves are thinking about the possibility of labour emigration, therefore, the survey on the sociocultural portrait of labour migrants in Russia aroused their genuine interest. The method of data collection is a questionnaire survey; the sample is quota-based by age; the restriction was also

Table 1. Assessment of relations with the host population by migrant workers with different travel frequency $(\mathrm{RF}, \%)$

\begin{tabular}{|l|c|c|c|c|}
\hline Agree / rather agree with the statement & Constant & Circular & $\begin{array}{c}\text { First-time } \\
\text { visitors }\end{array}$ & Total \\
\hline Russians treat migrants well & 70,1 & 72,9 & 75,1 & 72,2 \\
\hline $\begin{array}{l}\text { The residents of this town/village are } \\
\text { well-treated by migrants }\end{array}$ & 75,7 & 77,0 & 76,9 & 76,4 \\
\hline $\begin{array}{l}\text { I have a good relationship with the locals } \\
\text { where I live }\end{array}$ & 91,5 & 92,4 & 90,2 & 91,6 \\
\hline
\end{tabular}


mandatory training at Tambov State University named after G.R. Derzhavin.

\section{FINDINGS}

Respondents were asked for their opinion on the relevance of the problem of labour migration in Russia. $87 \%$ agree or rather agree that the problem is currently relevant. Only slightly more than $10 \%$ disagreed with this statement or found it difficult to answer.

Regarding the sources of information about migrant workers, the Internet $(41 \%)$ and personal observations $(36 \%)$ are mostly in the lead here. $13 \%$ of respondents noted that television has an impact on their opinion of migrant workers.

The next question was asked to determine the attitude of Tambov youth to the fact of attracting labour migrants to Russia. $71 \%$ of students said that it is more critical to increase labour productivity in Russia and use their labour resources than to attract workers from other countries. Only $14 \%$ expressed a positive opinion about attracting foreign labour, and they also offered their answers ("other"): "a small number of legal labour migrants should be encouraged", "should not be encouraged, but should not fight it either".

Young Tambov residents were asked to evaluate specific statements concerning various aspects of the "sociocultural portrait" of labour migrants in Russia.

The first group of statements concerned the Russian labour market:

1. Migrants create competition in the labour market and "take away" jobs from locals;

2. Migrants fill the shortage of workers in low-skilled and low-paid jobs;

3. It is necessary to support the entry of young and educated citizens, restricting the entry of disabled and poorly educated citizens from other countries.

The distribution of respondents responses can be seen in figure 1.

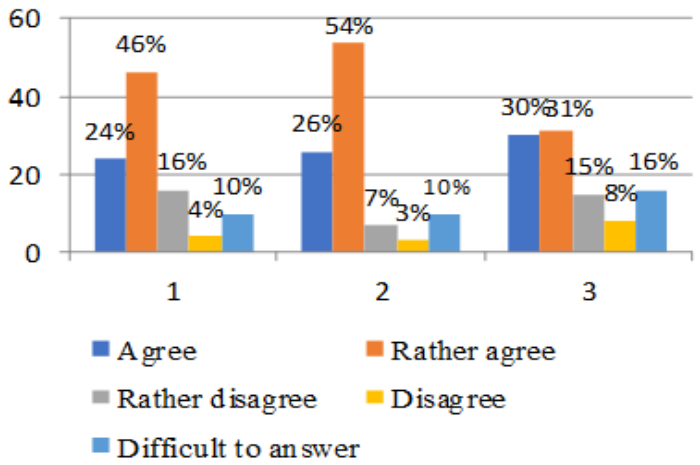

Figure 1 Distribution ratings of respondents' statements about the Russian labour market.
$70 \%$ of respondents agree or rather agree that migrant workers create competition for locals in the labour market, while $80 \%$ agree that foreign workers fill places in unclaimed, low-skilled and low-paid jobs.

However, more than half of the students surveyed $(61 \%)$ agreed to support the entry of only a part of citizens from other countries, namely, the most educated.

The next group of statements was related to attitudes to the lifestyle and values of migrant workers:

4. There are features in the way of migrants life that are difficult for locals of my city (village) to come to terms with;

5. Migrant workers escalate the crime increase;

6 . The spiritual values of newcomers undermine the foundations of our culture.

Respondents opinions on the labour migrants lifestyle were divided. $54 \%$ of respondents believe that there are specific aspects in the way of labour migrants life that are difficult for locals to come to terms with, $32 \%$ did not agree with this statement. The problem was caused by the statement about the connection of labour migrants with the increase in crime: $24 \%$ of respondents found it difficult to assess this statement. The opinions of other respondents were divided: $41 \%$ agree or rather agree with this judgment, $35 \%$ disagree. More than half of the students $(57 \%)$ do not believe that the spiritual values of migrant workers destroy the foundations of Russian culture. However, 33\% of respondents hold the opposite opinion.

Students were asked to create a "sociocultural portrait of a migrant", indicating the qualities that are most characteristic, in their opinion, for those who come to work in the Russian Federation. When answering this question, young Tambov residents note positive characteristics of migrants: hard work $(52 \%)$ and concern for the well-being of their families $(47 \%)$. At the same time, students noted such traits as lack of education (40\%) and selfishness, unwillingness to consider the new order and culture of the host country (42\%).

Predisposition to fraud and theft (16\%), as well as hostility (12\%) some respondents also singled out the answer options. In general, both positive and negative qualities are almost equally marked among the qualities inherent in labour migrants. The distribution is shown in figure 2 .

The central aspect that causes a negative attitude towards labour migrants is the fear of changes in the labour market, which may negatively affect locals.

In the next question, it was suggested to express their attitude to representatives of various ethnic groups who come to work in Tambov. The answer "I don't care" prevails for almost all ethnic groups represented. Respondents have the most positive attitude to labour 
migrants from China and Vietnam (31\%), Moldova $(28 \%)$ and Ukraine $(27 \%) ; 39 \%$ have a negative attitude to visitors from the North Caucasus, as well as to Tajiks, Uzbeks, and Kyrgyz (33\%), and a lesser extent - to Azerbaijanis (23\%). The persistent negative perception of these ethnic groups representatives who come to work is mostly influenced by the stereotypes promoted in mass culture and the media. At the same time, the image of migrants from China, Vietnam, Moldova and Ukraine does not have a sharply negative connotation.

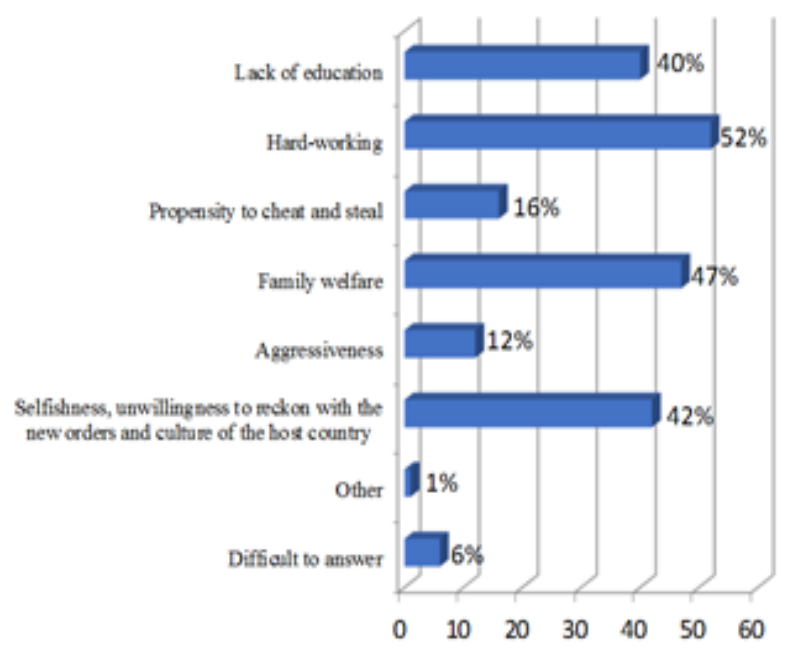

*more than $100 \%$ in total, since you could choose several options

Figure 2 Distribution of respondents opinions on the qualities inherent in labour migrants.

Finally, respondents were asked to choose the most effective, in their opinion, measures to improve the migration situation in Russia. Almost a third part of respondents $(32 \%)$ mentioned increased control by law enforcement agencies as the primary measure. In general, respondents tended to favour more stringent administrative measures than actions to help migrants in their sociocultural adaptation (fig. 3).

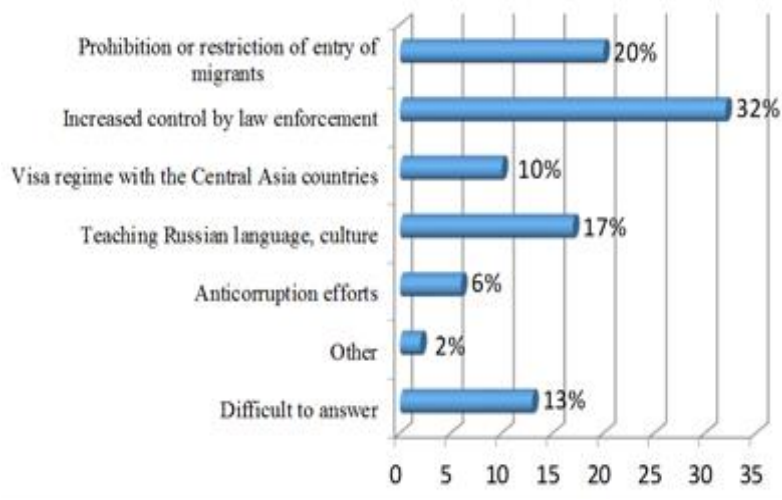

Figure 3 Distribution of respondents opinions on the most effective measures to improve the migration situation in Russia.

\section{CONCLUSION}

Based on the results of the author's empirical sociological research, the following conclusions are justified:

- Most respondents consider the problem of labour migration in Russia to be relevant at present;

- Describing labour migrants, respondents mainly note such positive qualities as hard work and concern for the well-being of the family, among the negative characteristics they highlight selfishness, unwillingness to reckon with the rules and culture of Russia, lack of education;

- Russians understand the need to attract foreign labour, but in the collective consciousness of a significant part of the Russian population, labour migrants are represented as poorly educated people who do not speak Russian and do not respect the traditions and norms of behaviour of the host country;

- Russians do not sufficiently understand the cultural values of migrants. Sometimes their persistent broadcasting in the Russian Federation causes hostility, irritation, distrust and fear, which are especially pronounced to those ethnic groups whose lifestyle and value system are radically different from those adopted in Russia.

- The attitude towards migrant workers is influenced by the ethnic factor, while it remains one of the main factors determining the tolerance of Russians to migrant workers. Negative attitude to those who come to work is more pronounced when it comes to representatives of the North Caucasus and Central Asia;

- The image of labour migrants in the minds of Russian youth is formed under the media influence, and above almostly, various Internet resources;

- Russians note the presence of specific features in the image of migrants, which are difficult for residents to get used to, although the spiritual values of migrants, according to the majority, do not pose a threat to the culture and spirituality of Russia.

Thus, to improve the situation with the regulation of labour migration in the Russian Federation, it is necessary a more detailed study of the influence of the sociocultural environment of the host society, adaptive capacity of labour migrants, social practices of interaction between the host population and authorities of migrant workers that require timely legal and administrative decisions. Obviously, today in Russia there is a need to develop a universal two-component policy of sociocultural adaptation and integration of immigrants, which should be built on the foundation of the priority of individual rights, regardless of which side this person represents (an immigrant or a citizen of the host society) and the unconditional preservation of the 
value and spiritual priorities of the traditional culture of the host society.

\section{REFERENCES}

[1] J.F. Rye, M.H. Slettebak, The new geography of labour migration: EU11 migrants in rural Norway, Journal of Rural Studies Vol. 75 (2020) 125-131.

[2] C. Leung, W. Karnilowicz, The psychological and sociocultural adaptation of chinese and vietnamese immigrant adolescents in Australia, International Perspectives on Child and Adolescent Mental Health Vol. 2 (2002) 519-539.

[3] S. Lissitsa, Y. Peres, Criteria of sociocultural adjustment: The case of the Russian Community in Israel since 1989, International Journal of Intercultural Relations Vol. 35 Iss. 2 (2011) 205212.

[4] A.A. Tarasyev, J.B. Jabbar, Dynamic Modeling of Labour Migration Impact on the Economic System Development, IFAC-PapersOnLine Vol. 51 Iss. 32 (2018) 407-412.

[5] A.V. Voropaeva, Sociocultural adaptation of immigrants in the context of integration into Russian society, Sociological science and social practice Vol. 7 Iss. 4 (2019) 128-135.

[6] A.L. Marshak, Adaptive policy of youth immigration: the experience of sociocultural analysis, SEARCH 5(64) (2017) 57-61.

[7] A.L. Marshak, S.V. Guzenina, Sociocultural practices of adaptation of immigrants: on the question of the integration potential of the host society, A.L. Marshak, S.V. Guzenina, Sociological science and social practice: a scientific journal 4 (2019) 139-153.

[8] L.M. Drobizheva, Variations of the population's adaptive potential to the growing ethnic diversity, Russia reforming: Yearbook [collection of scientific articles], ed. M.K. Gorshkov; Institute of sociology RAS. Moscow: New chronograph Iss. 14 (2016) 379-396.

[9] S.V. Guzenina, A.L. Marshak, Labour migration and interethnic tolerance: empirical accents of conflictogenicity, S.V. Guzenina, A.L. Marshak, Greater Eurasia: Development, security, cooperation. Yearbook. Issue 2. Ch. 2, RAS. INION. Scientific Department cooperation; Ed. Gerasimov V.I., Moscow, 2019, pp. 958-962.
[10] E. Nikiforova, O. Brednikova, On labour migration to Russia: Central Asian migrants and migrant families in the matrix of Russia's bordering policies Political Geography Vol. 66 (2018) 142-150.

[11] V.A. Volokh, T.N. Dmitrieva, Institutional forms of dialogue between the government and civil society in the context of the policy of integration of migrants (on the example of Moscow), Theories and problems of political research Vol. 6 Iss. 2A (2017) 420-431.

[12] K. Arshin, Risk management as a tool for migration regulating, EpSBS The European Proceedings of Social \& Behavioural Sciences Vol. 92 - SCTMG (2020) 94-104

[13] S. Ryazantsev, Labor Migration in Russia under Conditions of Integration in the Eurasian Economic Community, Voprosy Ekonomiki 6 (2008) 71-83. (In Russ.) DOI: https://doi.org/10.32609/00428736-2008-6-71-83

[14] V.I. Mukomel, Transformation of labour migration: social aspect, Russia is reforming, Yearbook/ed. edited by M.K. Gorshkov, M.: New chronograph Vol. 11 (2012) 236-263.

[15] A.L. Marshak, A.A. Gorbunov, A.V. Voropaeva, L.Yu. Korosteleva, Problems of sociocultural adaptation of immigrants in modern Russian society: expert dimension 6 (2018) 71-80.

[16] Tambov (Central Federal district), population in the spring of 2019 - 291,663 people. 